\title{
Lipid and lipoprotein profile changes in dairy cows in response to late pregnancy and the early postpartum period
}

\author{
Francesca Arfuso ${ }^{1}$, Francesco Fazio ${ }^{1}$, Maria Levanti ${ }^{1}$, Maria Rizzo ${ }^{1}$, Simona Di Pietro ${ }^{1}$, \\ Elisabetta Giudice ${ }^{2}$, and Giuseppe Piccione ${ }^{1}$ \\ ${ }^{1}$ Department of Veterinary Sciences, University of Messina, Polo Universitario Annunziata, \\ 98168, Messina, Italy \\ ${ }^{2}$ Department of Chemical, Biological, Pharmaceutical and Environmental Sciences, University of Messina, \\ Viale Ferdinando Stagno d'Alcontres 31, 98166, S. Agata-Messina, Italy
}

Correspondence to: Giuseppe Piccione (giuseppe.piccione@unime.it)

Received: 16 June 2016 - Revised: 11 October 2016 - Accepted: 18 October 2016 - Published: 31 October 2016

\begin{abstract}
In dairy cows the peripartum period involves endocrine and metabolic changes to compensate for the increased energy requirement aggravated by reduced feed intake. Cows adjust to the resulting negative energy balance with the mobilization of lipids from adipose tissue that, if excessive, could lead to many transition disorders compromising the offspring's growth and well-being. The aim of this study was to evaluate the dynamic changes in serum lipid and lipoprotein profiles in five dairy cows during the peripartum period. For each cow body condition score (BCS) and body weight (BW) measurements as well as blood sampling was carried out 60,30 and 15 days before calving $(-60,-30$ and $-15 \mathrm{BC})$, at calving day (C) and on days 15,30 and 60 after calving $(+15,+30$ and $+60 \mathrm{AC})$. Blood samples were tested for serum total lipids, phospholipids, triglycerides, very low-density lipoproteins (VLDLs), total cholesterol (Total-Chol), high-density lipoproteins (HDLs) and low-density lipoproteins (LDLs). One-way repeated measures analysis of variance (ANOVA) was applied to determine the effect of the peripartum period on the studied parameters in cows. A statistically significant effect of the peripartum period $(P<0.05)$ was found in the values of BCS, BW and all serum lipid and lipoprotein indices measured in cows. The changes observed in lipid indices of peripartum cows could be due to the start of milking and the increase in energy consumption in the body, confirming that metabolic adjustments occur as cows move from the gestation to the lactation period.
\end{abstract}

\section{Introduction}

In dairy cows pregnancy is recognized as inducing remarkable physiological and metabolic adaptations essential to ensure the suitable development of the foetus and to provide adequate substrates that are needed in utero and following birth (Modina et al., 2007; Van Dorland et al., 2009; Polakova et al., 2010).

Despite haemostatic mechanisms which function to maintain blood parameters within physiological levels, changes in biochemical indices occur as a result of increased metabolic demands during both pregnancy and lactation (Piccione et al., 2011).
In dairy cows the main changes in metabolic pathways normally begins approximately 3 weeks prior to calving; it is maximal at parturition and until 3 weeks after calving (Piccione et al., 2011). These periods are characterized by the mobilization of body fat, protein and mineral stores to satisfy the foetal demand for nutrients and the requirements for milk production and maintenance (Van Dorland et al., 2009).

Immediately before and after parturition as well as during the first stage of lactation, increased mammary gland activity results in energy deficiency, increased lipomobilization from body reserves and intensive ketogenesis and lipogenesis in the liver (Šamanc et al., 2010). The excessive fat mobilization can induce an imbalance in the hepatic carbohydrate 
and fat metabolism, which may result in metabolic disorders such as ketosis, which is related to other diseases including a retained placenta, uterine infection, milk fever and mastitis (Imhasly et al., 2015). Many transition period disorders, including fatty liver, also occur in a subclinical form affecting the overall health status, milk production and reproductive performance of dairy cows (Imhasly et al., 2015).

Because the lipid metabolism is a key aspect of the physiology and energy metabolism of transition cows (Drackley, 1999; Gross et al., 2013), the aim of this study was to investigate the dynamic changes in serum lipid and lipoprotein profiles in dairy cows during the peripartum period.

\section{Materials and methods}

\subsection{Farm conditions and animals}

Five multiparous Holstein cows (5-7 years) were selected from a farm located in Sicily, Italy $\left(36^{\circ} 42^{\prime} 38^{\prime \prime} \mathrm{N}\right.$ $14^{\circ} 47^{\prime} 15^{\prime \prime} \mathrm{E}$; $51 \mathrm{~m}$ above sea level). This area is characterized by a minimum and maximum mean annual temperature between 15.2 and $21.9^{\circ} \mathrm{C}$, mean annual relative humidity of $67.64 \%$, and mean annual rainfall of $35.6 \mathrm{~mm}$. The farm has a dry period of 60 days and a period of steaming up of 15 days before calving. The farm has a milk production of about $10000 \mathrm{~kg}$ per year, with a milk quality of $3.7 \%$ milk fat and $3.4 \%$ milk protein. All cows were clinically healthy and free from internal and external parasites. Their health status during pregnancy was evaluated based on rectal temperature, heart rate, respiratory profile, appetite, fecal consistency and hematological profile (data not shown). Over the first 3 days after calving each cow was subjected to a daily clinical examination including the evaluation of body temperature, heart rate, respiratory rate, external genitalia, vagina, cervix, uterus and ovaries (data not shown). All animals were kept in an indoor pen under a natural photoperiod and ambient temperature.

All cows were fed a balanced diet in accordance with the nutritional requirements of the peripartum period. Water was available ad libitum. Table 1 shows the chemical composition of diets used during dry period, steaming up and subsequent early lactation. The body condition scoring (BCS) was evaluated for each cow by the same operator using a 1 to 5 scale (Edmonson et al., 1989) throughout the monitoring period. The body weight (BW) of each animal was measured by means of a weighing platform (PS3000HD heavyduty floor scale, Breckwell, UK) throughout the monitoring period.

\subsection{Blood sampling and analysis}

Blood samples were collected from each animal by the same operator in the morning (07:00) by jugular venipuncture, and the blood was collected in Vacutainer tubes containing a cloth activator agent (Terumo Co., Tokyo, Japan). For
Table 1. Mean chemical composition (\%) of dairy cows' diets during dry period, final part of dry period (steaming up) and early lactation.

\begin{tabular}{lrrr}
\hline Composition (\%) & \multicolumn{3}{c}{ Period } \\
\cline { 2 - 4 } & Dry & Steaming up & $\begin{array}{r}\text { Early } \\
\text { lactation }\end{array}$ \\
\hline Crude protein & 12.43 & 13.87 & 16.66 \\
Ethereal extract & 4.18 & 4.55 & 5.32 \\
ASH & 7.55 & 7.83 & 7.34 \\
Neutral-detergent fibre & 50.45 & 43.99 & 33.41 \\
Non-fibre carbohydrates & 25.49 & 33.56 & 38.27 \\
Degradable dry matter & 52.38 & 59.68 & 68.22 \\
Acid-detergent fibre & 24.66 & 24.46 & 20.12 \\
Starch & 11.71 & 16.49 & 25.94 \\
Calcium & 0.39 & 0.41 & 0.98 \\
Phosphorus & 0.24 & 0.24 & 0.43 \\
Magnesium & 0.30 & 0.29 & 0.31 \\
Sodium & 0.10 & 0.11 & 0.62 \\
Potassium & 0.43 & 0.51 & 1.39 \\
Chlorine & 0.20 & 0.19 & 0.28 \\
Sulfur & 0.16 & 0.16 & 0.21 \\
\hline
\end{tabular}

each cow blood sampling was performed $60 \pm 3,30 \pm 3$ and $15 \pm 3$ days before calving ( $-60,-30$ and $-15 \mathrm{BC}$ ), at calving day $(\mathrm{C})$ and on days 15,30 and 60 after calving $(+15$, +30 and $+60 \mathrm{AC})$.

Blood samples were left at room temperature for $20 \mathrm{~min}$, and then they were centrifuged at $3000 \mathrm{rpm}$ for $10 \mathrm{~min}$; the obtained sera were stored at $-20^{\circ} \mathrm{C}$ until analysis. Only the non-haemolysed sera were analysed to estimate the concentration of total lipids, phospholipids, triglycerides, total cholesterol (Total-Chol), high-density lipoproteins (HDLs) and low-density lipoproteins (LDLs) using commercially available kits by means of an automated analyser UV spectrophotometer (model Slim SEAC, Florence, Italy). The very low-density lipoprotein fraction (VLDLs) was estimated as one fifth of the concentration of triglycerides (Lovejoy and Sainsbury, 2009).

All treatments, housing and animal care were carried out in accordance with the standards recommended by the EU Directive 2010/63/EU for animal experiments.

\subsection{Statistical analysis}

All results are expressed as mean \pm standard deviation (SD).

All data were tested for normality of distribution using the Shapiro-Wilks test. All data were normally distributed $(P>0.05)$, and statistical analysis was performed. One-way repeated measures analysis of variance (ANOVA), followed by a Bonferroni post hoc comparison test, was applied to determine the statistical effect of the peripartum period on BCS, BW, serum total lipids, phospholipids, triglycerides, TotalChol, HDLs, LDL and VLDL values measured in cows. $P$ 
Table 2. Mean values ( \pm SD) of body weight $(B W)$ and body condition score (BCS) obtained from cows at $60 \pm 3,30 \pm 3$ and $15 \pm 3$ days before calving ( $-60,-30$ and $-15 \mathrm{BC}$ ), at calving day (C) and at 15, 30 and 60 days after calving $(+15,+30$ and $+60 \mathrm{AC})$.

\begin{tabular}{llll}
\hline \multirow{2}{*}{ Cows } & \multicolumn{2}{c}{ Measurement } \\
\cline { 3 - 4 } & & $\mathrm{BW}(\mathrm{Kg})$ & $\mathrm{BCS}$ \\
\hline Days relative & $-60 \mathrm{BC}$ & $631.3 \pm 46.7$ & $3.25 \pm 0.25$ \\
to parturition & $-30 \mathrm{BC}$ & $643.6 \pm 41.8^{\mathrm{b}}$ & $3.25 \pm 0.25$ \\
& $-15 \mathrm{BC}$ & $655.2 \pm 44.9^{\mathrm{b}, \mathrm{c}}$ & $3.25 \pm 0.25$ \\
& $P$ & - & $3 \pm 0.25$ \\
& $+15 \mathrm{AC}$ & $581.5 \pm 38.7^{\mathrm{a}}$ & $2.75 \pm 0.25^{\mathrm{a}, \mathrm{d}}$ \\
& $+30 \mathrm{AC}$ & $578.9 \pm 41.5^{\mathrm{a}}$ & $2.75 \pm 0.25^{\mathrm{a}, \mathrm{d}}$ \\
& $+60 \mathrm{AC}$ & $575.8 \pm 45.4^{\mathrm{a}}$ & $2.5 \pm 0.25^{\mathrm{a}, \mathrm{d}}$ \\
\hline
\end{tabular}

Significances $(P<0.0001):^{a}$ vs. 60,30 and $15 \mathrm{BC}$; ${ }^{\mathrm{b}}$ vs. $60 \mathrm{BC}$; ${ }^{\mathrm{c}}$ vs. $30 \mathrm{BC}$; ${ }^{\mathrm{d}}$ vs. $P$

values $<0.05$ were considered statistically significant. Data were analysed using the software Prism v. 4.00 (Graphpad Software Ldt., USA, 2003).

\section{Results}

None of the animals included in the study showed clinical signs of disease during the monitoring period. All cows delivered healthy, viable full-term calves, without assistance. They passed a normal and intact placenta spontaneously within $2 \mathrm{~h}$ and achieved the complete involution of the uterus within 2 weeks after calving.

$\mathrm{BW}$ and $\mathrm{BCS}$ values measured in cows during the peripartum period are shown in Table 2 with the related significances found. As expected, prepartum BW and BCS values recorded from cows were statistically higher with respect to postpartum time points $(P<0.0001)$. Within the prepartum interval a difference was found in BW over time $(P<0.0001)$. One-way ANOVA revealed a statistically significant effect of the peripartum period on all serum lipid and lipoprotein indices measured in cows. In particular, serum total lipids and phospholipids showed decreased values from prepartum time points until calving, followed by an increase throughout the postpartum time points $(P<0.001)$. Triglycerides and VLDLs showed the highest levels during the prepartum time points; afterwards, they showed the same declining trend until 15 and 30 days after calving $(P<0.001)$ Total-Chol and LDLs showed the highest values 60 days before calving followed by a decrease throughout the monitoring period $(P<0.05)$. The HDLs showed the highest values during the prepartum time points with respect to 15 and 30 days after calving $(P<0.05)$ (Fig. 1).

\section{Discussion}

During the peripartum period there is an increase in the demand for the regulatory mechanism responsible for the processes involved in milking (Krajnicakova et al., 2003). For this reason, characteristic changes in lipid metabolism are found during pregnancy and lactation in most mammals (Roche et al., 2009). Endocrine profiles change and lipolysis and lipogenesis are regulated to increase the lipid reserve during pregnancy, which will be utilized following parturition and the initiation of lactation (Roche et al., 2009). This agrees with the higher BCS values measured in cows at the prepartum time points and lower BCS values evaluated in cows at the postpartum time points. The best BCS at calving is between 3.0 and 3.25 (five-point scale). Below a BCS of 3.0, cows produce less milk, are less likely to get pregnant and are more likely to present with symptoms that place them in an animal welfare risk category. Above a BCS of 3.25, cows have a reduced dry matter intake, produce less milk and are more likely to succumb to periparturient metabolic disorders (Roche et al., 2009). It has been demonstrated that dairy cattle with high BCS (BCS > 4.0; using a scale of 15 ) in the last 3 weeks of gestation had a much greater depression in feed intake during the immediate prepartum period when compared to cows with lower BCS (Hayirli et al., 2002). During early lactation, cows are in a negative energy balance and body reserves are an important fuel supply to assist the cow in reaching her genetic potential for milk synthesis (Grummer, 1995). This agrees with the changes found in lipid profile of peripartum cows. In particular, a drop in serum total lipids and phospholipid values was found in cows at calving time compared to prepartum followed by an increase throughout the postpartum time points. In contrast, a decrease in serum triglycerides and VLDL values was found at calving and postpartum time points compared to prepartum time points. The changes found in these parameters agree with the results of previous studies (Imhasly et al., 2015; Van den Top et al., 2005; Kessler et al., 2014).

A common feature of phospholipids is their requirement for the secretion of hepatic triglycerides as VLDLs, indicating that a reduced level of phospholipids may directly cause an excessive accumulation of triglycerides in the liver (Artegoitia et al., 2014; Côté et al., 2014). The temporary drop in phospholipids levels on the day of parturition may be due to an increase in phospholipase activity in order to gain energy (Jacobs et al., 2013). In addition to insufficient hepatic VLDL secretion, the decrease in triglyceride levels and concomitant rise in phospholipids after parturition may be due to an increase in mammary lipoprotein lipase activity (Van den Top et al., 2005) in order to satisfy the energy requirements and the fat mammary gland transfer for milk yield (Fiore et al., 2014; Imhasly et al., 2015). Serum Total-Chol and LDL values showed a decrease from the prepartum to the postpartum period, whereas HDLs showed lower values 15 and 30 days after calving with respect to prepartum. 

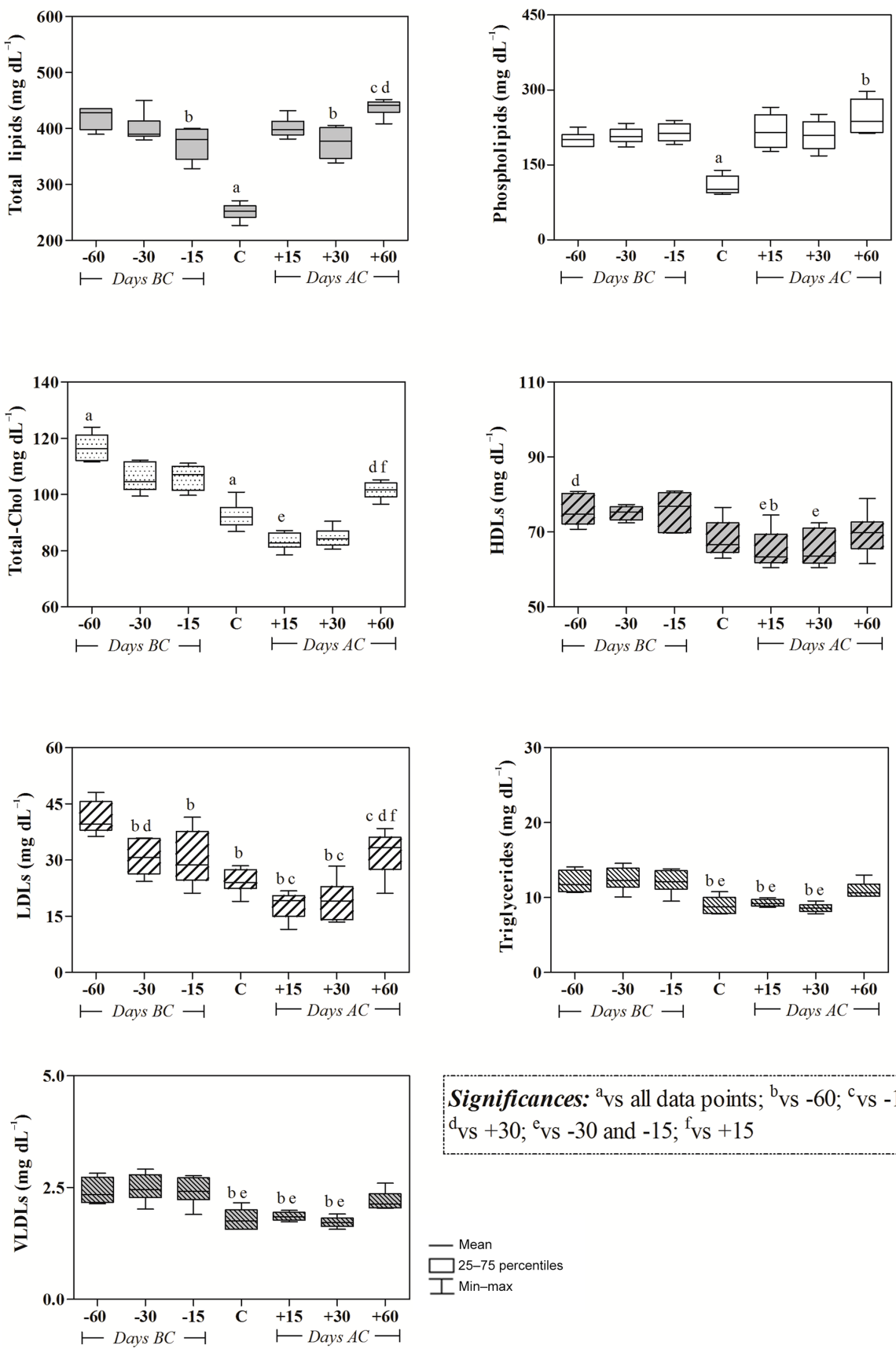

Significances: ${ }^{\mathrm{a}} \mathrm{vs}$ all data points; ${ }^{\mathrm{b}} \mathrm{vs}-60 ;{ }^{\mathrm{c}} \mathrm{vs}-15 ;$
$\mathrm{d}_{\mathrm{vS}}+30 ;{ }^{\mathrm{e}} \mathrm{vs}-30$ and $-15 ;{ }^{\mathrm{f}} \mathrm{vS}+15$

Figure 1. Trends and related statistical significances of serum total lipids, phospholipids, total cholesterol (Total-Chol), high-density lipoproteins (HDLs), low-density lipoproteins (LDLs), triglycerides and very low-density lipoproteins (VLDLs) observed in cows at $60 \pm 3,30 \pm 3$ and $15 \pm 3$ days before calving $(-60,-30$ and $-15 \mathrm{BC})$, at calving day $(\mathrm{C})$ and at 15,30 and 60 days after calving $(+15,+30$ and $+60 \mathrm{AC})$.

The liver plays a central role in the maintenance of wholebody cholesterol homeostasis by integrating the regulation of a group of hepatic enzymes, receptors and other proteins important for cholesterol and lipoproteins metabolism. Hepatic regulatory elements and their integration for the maintenance of cholesterol homeostasis undergo major changes during pregnancy and lactation to ensure that cholesterol homeosta- sis is maintained optimally for both the mother and the developing offspring (Smith et al., 1998; Cupps, 1991). For this purpose, lipoproteins become necessary because cholesterol is bound to these compounds in the bloodstream.

The decrease in Total-Chol concentration throughout prepartum period might have resulted from the utilization of cholesterol by steroidogenic endocrine organs, including 
the ovaries and placenta for steroid hormone synthesis during pregnancy (Cupps, 1991), whereas the decrease in serum Total-Chol after calving might be due to lactation (Cupps, 1991). In our study, the concentrations of serum Total-Chol and LDLs paralleled each other because the LDL pathway is the primary pathway by which cells of the ovary, placenta and mammary gland acquire cholesterol to synthesize steroids and to produce milk (Cupps, 1991). Effectively, cholesterol in milk derives from LDL lipoproteins as well as from de novo synthesis in the mammary gland (Symonds and Stephenson, 1999). Therefore, the changes in serum TotalChol and LDL levels found in peripartum cows suggest that LDLs are cleared from the circulation during pregnancy and the lactating phase to compensate for the needs of the ovary, placenta and mammary glands.

\section{Conclusions}

The transition from gestation to lactation is a stressful experience for dairy cows since several metabolic and endocrine adjustments occur during the peripartum period. The improved understanding of metabolic demands during the peripartum period might assist in monitoring the health status of the cows in order to promote the offspring's growth and wellbeing.

The results obtained in the present study revealed a serum lipid and lipoprotein dynamic modification in peripartum cows. The main changes observed in lipid indices of peripartum cows could be due to the start of milking and the increase in energy consumption in the body.

Competing interests. The authors declare that they have no conflict of interest.

Author contributions. All authors made substantial contributions to each step of the experimental procedure and paper preparation. In particular, Francesca Arfuso prepared the paper and performed the laboratory analysis, Francesco Fazio and Maria Rizzo performed the sampling and analysed the data, Simona Di Pietro and Elisabetta Giudice contributed to the experiment design, and Giuseppe Piccione supervised all stages of the experimental study.

Edited by: S. Maak

Reviewed by: V. Nagyova, M. Gianesella, and V. Carcangiu

\section{References}

Artegoitia, V. M., Virginia, M., Middleton, J. L., Harte, F. M., Campagna, S. R., and de Veth, M. J.: Choline and choline metabolite patterns and associations in blood and milk during lactation in dairy cows, PLoS One, 8, e103412, doi:10.1371/journal.pone.0103412, 2014.
Côté, I., Chapados, N., and Jean-Marc, L.: Impaired VLDL assembly: a novel mechanism contributing to hepatic lipid accumulation following ovariectomy and high-fat/high-cholesterol diets?, Br. J. Nutr., 112, 1592-1600, 2014.

Cupps, P. T.: Reproduction in domestic animals, Academic Press, San Diego, New York, Boston, Toronto, London, Sidney, Tokyo, 81-118, 1991.

Drackley, J. K.: Biology of Dairy Cows During the Transition Period: The Final Frontier?, J. Dairy Sci., 82, 2259-2273, 1999.

Edmonson, A. J., Lean, I. J., Weaver, L. D., Farver, T., and Webster, G.: A body condition scoring chart for Holstein dairy cows, J. Dairy Sci., 72, 68-78, 1989.

Fiore, E., Gianesella, M., Arfuso, F., Giudice, E., Piccione, G., Lora, M., and Stefani, A.: Morgante M. Glucose infusion response on some metabolic parameters in dairy cows during transition period, Arch. Tierzucht, 57, 1-9, 2014.

Gross, J. J., Schwarz, F. J., Eder, K., van Dorland, H. A., and Bruckmaier, R. M.: Liver fat content and lipid metabolism in dairy cows during early lactation and during a mid-lactation feed restriction, J. Dairy Sci., 96, 5008-5017, 2013.

Grummer, R. R.: Impact of changes in organic nutrient metabolism on feeding the transition cow, J. Anim. Sci., 73, 2820-2833, 1995.

Hayirli, A., Grummer, R. R., Nordheim, E. V., and Crump, P. M.: Animal and dietary factors affecting feed intake during the prefresh transition period in Holsteins, J. Dairy Sci., 85, 3430-3443, 2002.

Imhasly, S., Bieli, C., Naegeli, H., Nyström, L., Ruetten, M., and Gerspach, C.: Blood plasma lipidome profile of dairy cows during the transition period, BMC Vet. Res., 11, 252, doi:10.1186/s12917-015-0565-8, 2015.

Jacobs, R. L., van der Veen, J. N., and Vance, D. E.: Finding the balance: the role of S-Adenosylmethionine and phosphatidylcholine metabolism in development of nonalcoholic fatty liver disease, Hepatology, 58, 1207-1209, 2013.

Kessler, E. C., Gross, J. J., Bruckmaier, R. M., and Albrecht, C.: Cholesterol metabolism, transport, and hepatic regulation in dairy cows during transition and early lactation, J. Dairy Sci., 97, 5481-5490, 2014.

Krajnicakova, M., Kovac, G., Kostecky, M., Valocky, I., Maracek, I., Sutiakova, I., and Lenhardt, L.: Selected clinic-biochemical parameters in the puerperal period of goats, B. Vet. I. Pulawy, 47, 177-182, 2003.

Lovejoy, J. C. and Sainsbury, A.: Sex differences in obesity and the regulation of energy homeostasis, Obes. Rev., 10, 154-167, 2009.

Modina, S., Abbate, F., Germanà, G. P., Lauria, A., and Luciano, A. M.: $\beta$-Catenin localization and timing of early development of bovine embryos obtained from oocytes matured in the presence of follicle stimulating hormone, Anim. Prod. Sci., 100, 264-279, 2007.

Piccione, G., Messina, V., Schembari, A., Casella, S., Giannetto, C., and Alberghina, D.: Pattern of serum protein fractions in dairy cows during different stages of gestation and lactation, J. Dairy Res., 78, 421-425, 2011.

Polakova, K., Kudrna, V., Kodes, A., Hucko, B., and Mudrik, Z.: Nonstructural carbohydrates in the nutrition of high yielding dairy cows during a transition period, Czech J. Anim. Sci., 55, 468-478, 2010. 
Roche, J. R., Friggens, N. C., Kay, J. K., Fisher, M. W., Stafford, K. J., and Berry, D. P.: Invited review: Body condition score and its association with dairy cow productivity, health, and welfare, J. Dairy Sci., 92, 5769-5801, 2009.

Šamanc, H., Stojić, V., Kirovski, D., Jovanović, M., Cernescu H., and Vujanac I.: Thyroid hormones concentrations during the mid-dry period: an early indicator of fatty liver in Holstein-Friesian Dairy Cows, J. Thyroid Res., 2010, 897602, doi:10.4061/2010/897602, 2010.

Smith, J. L., Lear, S. R., Forte, T. M., Ko, W., Massimi, M., and Erickson, S. K.: Effect of pregnancy and lactation on lipoprotein and cholesterol metabolism in the rat, J. Lipid Res., 39, 22372249, 1998.
Symonds, M. E. and Stephenson, T.: Maternal nutrient restriction and endocrine programming of fetal adipose tissue development, Biochem. Soc. Trans., 27, 97-103, 1999.

Van den Top, A. M., Van Tol, A., Jansen, H., Geelen, M. J., and Beynen, A. C.: Fatty liver in dairy cows post partum is associated with decreased concentration of plasma triacylglycerols and decreased activity of lipoprotein lipase in adipocytes, J. Dairy Res., 72, 129-137, 2005.

Van Dorland, H. A., Richter, S., Morel, I., Doherr, M. G., Castro, N., and Bruckmaier, R. M.: Variation in hepatic regulation of metabolism during the dry period and in early lactation in dairy cows, J. Dairy Sci., 92, 1924-1940, 2009. 